pneumococcal lesion. Now that attention has been called to it it will probably be found to occur more frequently than was formerly thought. Thus Raw ${ }^{19}$ has met with seven cases following pneumonia-i.e., in about 1 per cent. Dudgeon and Branson ${ }^{20}$ have carefully described five cases seen in a short space of time at the East London Hospital, Shadwell. Yet we have only been able to find three cases of arthritis at St. Bartholomew's Hospital during the last ten years proved to be due to the pneumococcus alone. In two cases the knee was attacked, in the third the shoulder and wrist. It usually appears during the height of the primary disease. ${ }^{21}$ Despite the grave prognosis the constitutional symptoms are not usually so severe as in streptococcal infections. ${ }^{22}$ Generally, it is the synovial membrane that is attacked, though sometimes the suppuration spreads to the periarticular tissues, as in the present case. The fluid may be thin or creamy pus or almost clear fluid inclosed in a gelatinous membrane. Dudgeon and Branson ${ }^{23}$ attach prognostic importance to this, thin pus being an unfavourable sign. whereas encapsulation of the fluid is a good omen. Edema or brawny induration in the neighbourhood of the affected joint is frequently absent. If the bone is attacked it is generally the outer part near the epiphyseal line that suffers. Pneumococcal osteomyelitis has not as yet been described. The knee is the joint most commonly attacked. Though usually confined to one or two joints the arthritis and osteitis may become wide-spread. Thus in a case recorded by Murray ${ }^{2+}$ the knee, thigh, ankle, and leg were all attacked.

Vulvitis.-This only appeared after the opening of the abdomen; it must have often happened that the profuse discharge ran down on to the vulva. It yielded to simple antiseptic lotions, so in all probability this was simply an accidental contamination and sprang from no deep-seated cause. But, as has been already pointed out, pneumococcic endometritis may occur and, indeed, all the mucous surfaces have been attacked by this organism ${ }^{2} \overline{ }$ In the series of cases here recorded the endometrium was involved once and the Fallopian tubes twice.

In conclusion we have tabulated the 39 fatal cases occurring at St. Bartholomew's Hospital between January, 1894, and August, 1904, of multiple lesions bacteriologically proved to be due to the pneumococcus alone (Table I.). As there is some difference of opinion as to what is sufficient evidence on this point, the pathological report is appended in each case. In calculating the percentages we have added to this table (see Table II.) the case ${ }^{26}$ that recovered. Even when all the clinical and post-mortem evidence has been taken into account, it is sometimes difficult to decide which was the primary lesion, and the table only indicates what was the probable course of events.

\section{TABLE II.}

\section{Primary Discoverable Lesion.}

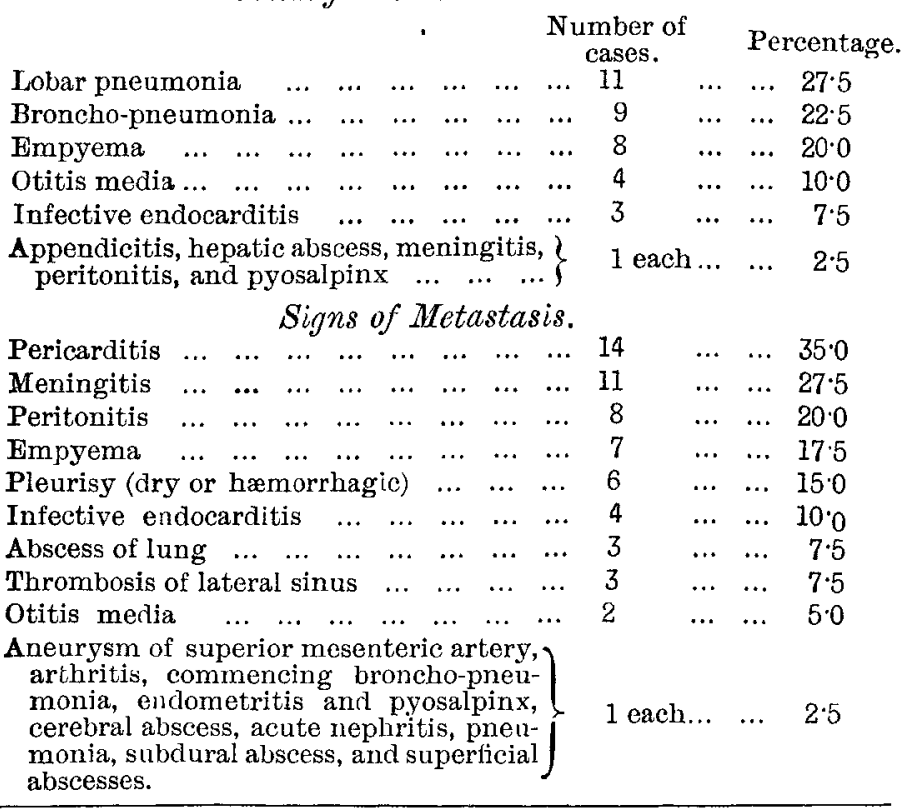

19 Raw : Brit. Med. Jour., 1901, vol. ii., p. 1803 20 Dudgeon and Branson: THE LANCET, August 1st, 1903, p. 316.
21 Pisterer : Jahresbericht fur Kinderheilkunde, Band v., Hett 4, S. 417 .

22 D adgeon and Branson: The Lancert, August 1st, 1903, p. 316

$$
\begin{aligned}
& \text { me LanceT, August 1st, 1903, } \\
& 2 \text { Ibid. } \\
& \text { AnCFi, June 7th, 1902, p. } 1604 .
\end{aligned}
$$

25 Foulerton: THF LANCET, April 12th, 1902, p. 1027. Cary and Lyons

Am riean Journal of the Medical Sciences, vol. cxxii., 1901, p. 298.

\section{NOTES ON A CASE OF QUADRUPLETS.}

BY ANNIT C. GOWDEY, M.B. LOND.,

ASSIS'TANT MEDICAL SUPERINTENDEN'T, S'I, I'ANCRAS INFIRMARY (SOLI'H).

CASES of four children at one birth occur with such extreme rarity as to justify the publication of this note. According to Fothergill the ratio is 1 in 387,000 .

The patient, aged 36 years, was admitted to the lyingin ward on Sept. 15th, 1904, at 8 P.M. She stated that at 3 o'clock the same afternoon while lifting a heavy saucepan off the fire she felt something "snap" inside her. Soon after a considerable quantity of fluid came from her which she attributed to a temporary loss of control over the bladder. Pains which she described as "slight and lingering" began a few hours after and she left her work and went to the St. Pancras Infirmary.

On admission she gave a history of five and a half months' pregnancy and of having quickened about a month previously. She hacl noticed herself unusually large but had no pressure symptoms other than a great feeling of heaviness and difficulty in stooping. On examination the abdomen was greatly distended, the upper limit of the uterus being three fingers' breadth below the ensiform cartilage; the foetal parts were not satisfactorily felt. 'There was a loud uterine souffle on the right side but no fcetal heart sound could be detected. The os was dilated, the membranes having ruptured, and a fotal head, soft, as if unossified, was felt towards the right side. The cord, which was prolapsed and pulsating, was easily returned. Pains had now subsided, but as the woman appeared extremely comfortable interference was deemed unnecessary. The patient had a good night and slept well. About 3 A.M. a few slight niggling pains were felt. She was seen again at 9.30 A.M. when the child was found to be presenting transversely in the dorsoanterior position; the hand prolapsed outside the vagina could not be returned. Forceps were applied to the breech and delivery was rapid and easy. The child, a female, measured 13 inches long, weighed 1 pound 4 ounces, and survived 13 hours. Shortly afterwards uterine contractions returned and within the next 20 minutes three other children, two males and one female, were expelled. These were all stillborn and of them the first was a breech presentation, the next a transverse with arm prolapsed, as in the first case of all and the last a vertex. In length they measured $12 \frac{1}{4}, 13$, and $11_{\frac{1}{2}}$ inches respectively and their weights were 1 pound 10 ounces and 1 pound 4 ounces each of the remaining two. After another 20 minutes the placentæ were delivered, the last one manually. Two were quite separate. The remaining two had coalescing margins with separate chorions to each. There were no complications and the patient made a rapid recovery.

As regards her former history the patient had had five previous pregnancies, none of which were multiple; there had been severe hæmorrhage in two of these. On the mother's side is a complete absence of any constitutional or hereditary tendency ; the paternal influence is difficult to obtain.

Remarks.-Cases of multiple pregnancy are notoriously liable to post-partum hæmorrhage, mainly for two reasonsan over-distended uterus favouring inertia and the presence of a large placental site. In this case post-partum hæmorrhage was conspicuous by its absence. This is all the more surprising when one considers the unusually prolonged second stage, coupled with the fact that in previous preg. nancies she suffered severely from this complication. The very prolonged delay in the second stage of labour in this instance can readily enough be explained by the overdistension of the uterus, a condition brought about by the two factors present-viz., the plural pregnancy and the considerable amount of hydramnios.

Anomalies of presentation and also premature labour are the rule rather than the exception in multiple pregnancies. The case in point well illustrates both these, for of the presentations two were transverse and one was a breech. As regards the duration of pregnancy, judging by the appearances presented by the infants, it was probably six and a half months, although the mother denied a longer period than five and a half months.

A further point worth noting is the uniovular development of each child, as indicated by the presence of separate 
chorions. This is the most common mode of development in the case of twin pregnancies (Galabin), but is unusual in multiple pregnancies involving more than two children.

I am indebted to Dr. W. M. Dunlop, the medical superintendent of the infirmary, for his kind permission to publish this"case.

St. Pancras Infirmary.

\section{SOME CASES FROM PROFESSOR GAUCHER'S CLINIC AT THE HÔPITAL ST. LOUIS, PARIS}

BY J. L. BUNCH, M.D., D.Sc. LOND.

THE cases from which the following notes were made were seen by me during the first six months of this year and my thanks are due to Professor Gaucher for permission to publish the notes.

Diagnosis and treatment of lupus erythematosus of the scalp. - The patient, a young girl, had on her scalp some plaques of cicatricial appearance, in one of which were found all the signs of lupus erythematosus, although the largest had lost its characteristic appearance by reason of the treatment which it had undergone and which had caused it to be covered with impetiginous crusts. Diagnosis was necessary between lupus erythematosus and the other diseases which cause cicatricial alopecia of the scalp-traumatic alopecia, favus, and folliculitis decalvans. In favus the cicatrices are deeper and more irregular; at first they are not red, then they take on a whitish tint, and as a rule the cicatrices are large. Folliculitis decalvans causes small round cicatrices surrounded by a bald patch, the cicatrices being more numerous but smaller than those consecutive to favus. In the case of lupus erythematosus the lesions may be multiple and although larger than those of folliculitis decalvans they do not attain to the dimensions of those of favus. Their centre presents a cicatricial depression and their periphery shows a red scaly border, which is infiltrated and is characteristic of the extending zone of lupus erythematosus. One of the patches on this patient's scalp presented all these characteristics.

The treatment of lupus erythematosus of the scalp does not differ from that of the affection in other localities. Professor Gaucher orders the diseased surface to be bandaged with a mixture of equal parts of tincture of iodine and crystallised acetic acid, which causes a certain amount of inflammation of the diseased area. Highfrequency currents are also applicable to the treatment of lupus erythematosus of the scalp. They are, as a rule, well supported by the patient and do not cause painful or unpleasant sensations, even on the face. One patient in this clinic has, however, been unable to stand highfrequency currents applied to the face; she complained of the pain and in consequence the treatment had to be abandoned. But such a case is the exception. In every case it must not be omitted to warn the patient that the disease is one which tends to recur and that future treatment will probably be necessary.

Pityriasis rosea of Gibert abnormally pigmented.-It is unusual for pityriasis rosea to leave a very pronounced pigmentation after its elements have disappeared. Such an anomaly of the pityriasic eruption may cause confusion and lead to the suspicion of the existence of a syphilide which is fading. In the present case each of the elements of the pityriasis had been followed by a dark brown mark and an exact diagnosis could only be made after a very careful examination. The absence of any antecedent, of any trace of genital ulceration, or of mucous lesions led, however, to the elimination of the hypothesis of syphilis. On the anterior surface of the right thigh we succeeded in discovering a unique medallion characteristic of pityriasis rosea, which made the diagnosis certain. On the genital organs the affection had caused the development of a slight amount of eczematisation.

Cicatricial acne pilaris of difficult diagnosis.-In a girl, aged 23 years, patches of cicatricial lesions were present on the forehead and on the outer surface of the nose and on the chin; they were prominent and presented a slightly keloid appearance. The patient stated that they had succeeded some small nodules covered with thin scabs which made their appearance a few months previously and were treated with the galvano-cautery. What was actually seen now was the result of this operative treatment and the diagnosis was therefore by no means easy, for the lesions no longer showed any trace of morbid activity.

If one inquires what are the lesions of the face usually treated by galvano-cauterisation one thinks naturally of lupus, but the rapid evolution of the lesions is not in favour of this diagnosis. On the other hand, acne is often treated by this method also and in the case before us the lesions were of this nature. In fact, at the edge of the scalp there were some pustular lesions which were those of cicat ricial acne pilaris, the "acne necrotica or varioliformis," of German authors. On the scalp similar lesions were also present.

Professor Gaucher does not approve of the treatment of acne by the galvano-cautery. He has seen it from line to time, as in the present case, cause hypertrophied, almost keloid, scars. The pus contained in the acne elements should rather be evacuated by a short scarificator which is quite as effectual as the galvano-cautery and does not cause ugly scars. Moreover, the medicaments subsequently prescribed for the skin should contain no irritating substances.

A case of melanodermia papillomatosa or acanthosis nigricans.--The patient, a man, aged 51 years, was of Greek nationality. As regards his past history, in the year 1873 he lived in Italy and contracted typhoid fever. Three months afterwards he had cholera. In 1884 he had hæmoptysis and in 1889 pulmonary congestion. Since that time he had had a cough and from time to time spat blood. Examination of the skin showed (1) pigmentation of various regions ; (2) papillomata; and (3) nævi and senile mollusca. The pigmentation on the neck was very marked, distinctly brown in colour, varying from a deep dark tint to a fainter coffee colour near the edges. Over the area of pigmentation the folds of the skin were more marked and the intervening sulci were deeper than normal. The mammæ were prominent and pigmented. The skin of the axillæ was darkish-brown and thickened. The dorsal surfaces of the hands were deeply pigmented, the pigmentation extending to a lesser degree on to the posterior surface of the forearm on both sides. The skin of the genito-anal region showed rugosities, was dark brown, and in places almost black. Papillomata were present on the dorsa of the hands and at the anterior borders of the axillæ. Nævi were found scattered over the pigmented areas, brown, black, or café au lait in colour. Palpation of the abdomen showed a definite tumour in the left hypochondriac region, slightly tender on deep pressure, involving probably the posterior surface of the stomach. It was considered to be cancerous. The subclavicular and inguinal glands were enlarged. The lungs showed definite signs of tuberculosis. Not more than 20 cases of this disease are known and the prognosis is bad.

Papular cutaneous tuberculosis.-A young man, aged 20 years, presented some scabbed papular lesions on the knees and posterior surface of the forearms. The lesions were those of a papular tuberculosis of the skin, non-bacillary cutaneous tuberculosis, which some authors describe under the name of tuberculides. The dermatosis was one which by reason of its origin and nature might up to a certain point be considered as allied to lupus erythematosus. In this case the diagnosis was easy, for the patient was suffering from tukerculous glands of the neck, and hence the nature of the cutaneous affection could be deduced. The lungs, however, showed no signs of tuberculosis. The diagnosis would be infinitely more difficult if no glandular, visceral, or bone lesions of tuberculosis were present. The lesions therefore present some resenblance to lichen but they are dissimilar in that the centres of the papules show a cicatricial depression which is not seen in lichen. Moreover, each is covered with a scab and when this falls off an indelible scar remains.

Chronic prurigo of late development.-The lesions of chronic prurigo were here seen in the usual distribution in a girl, aged 17 years. But although the distribution was not abnormal the case is peculiar in that the first manifestations of the disease showed themselves only a year ago when the girl was 16 years old. As a rule, prurigo commences very much earlier in life and is usually a disease of infancy. Cases such as this when the first signs show themselves after adolescence are distinctly rare but they do occur. Treatment consists in the use of cod-liver oil internally and externally and the patient will be treated with inunctions of cod-liver oil and she will have to take several spoonfuls a day. In cases where there is much lichenification and 